\title{
Medievalista
}

Online

$30 \mid 2021$

Número 30

Tipos, usos y significadosTese de Doutoramento em Estudos

Medievais apresentada à Universidade de Santiago de Compostela

em março de 2020. Dirigida por las Profesoras Marta Cendón

Fernández y María Luz Ríos Rodríguez

\section{La imagen escultórica del Crucificado en la Galicia del siglo XIV}

Tipos, usos y significados. Tese de Doutoramento em Estudos Medievais apresentada à Universidade de Santiago de Compostela em Março de 2020. Orientação das Professoras Marta Cendón Fernández e María Luz Ríos Rodríguez

\section{Sara Carreño}

\section{OpenEdition}

Journals

Edición electrónica

URL: https://journals.openedition.org/medievalista/4590

DOI: $10.4000 /$ medievalista.4590

ISSN: $1646-740 \mathrm{X}$

Editor

Instituto de Estudos Medievais - FCSH-UNL

\section{Referencia electrónica}

Sara Carreño, «La imagen escultórica del Crucificado en la Galicia del siglo XIV», Medievalista [En línea] 30 | 2021, Publicado el 01 julio 2021, consultado el 04 abril 2022. URL: http://journals.openedition.org/ medievalista/4590 ; DOI: https://doi.org/10.4000/medievalista.4590

Este documento fue generado automáticamente el 4 abril 2022.

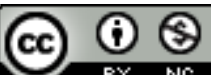

Mediavalista está licenciado com uma Licença Creative Commons - Atribuição-NãoComercial 4.0 Internacional. 


\section{La imagen escultórica del Crucificado en la Galicia del siglo XIV}

Tipos, usos y significados. Tese de Doutoramento em Estudos Medievais apresentada à Universidade de Santiago de Compostela em Março de 2020. Orientação das Professoras Marta Cendón Fernández e María Luz Ríos Rodríguez

\section{Sara Carreño}

\section{NOTA DEL EDITOR}

Data recepção do artigo / Received for publication: 31 de Janeiro de 2020

1 El propósito de esta tesis doctoral es estudiar los usos y significados que tuvieron las diversas representaciones escultóricas de Cristo crucificado dentro de la cultura religiosa de la Galicia del siglo XIV ${ }^{1}$. Para ello, este trabajo se aproximó a la realidad visual, material y cultural de los siglos bajomedievales en Galicia partiendo de una imagen que remite de forma directa al misterio central del cristianismo, sintetizando la esperanza de los fieles cristianos en la posible salvación eterna tras la muerte. Además, esta tesis busca examinar hasta qué punto el caso gallego se adapta a las dinámicas presentes en otros territorios del Occidente medieval cristiano. Esta aproximación no solo permite conocer el papel que las imágenes jugaron dentro de su sistema cultural, sino que también nos ofrece una visión panorámica de las experiencias de quienes vivieron en la Galicia de finales de la Edad Media. 
2 La inabarcable amplitud del objeto de estudio obligó a restringir el corpus a través de una serie de delimitaciones que, aunque puedan resultar rígidas y artificiales -pues distorsionan la realidad pasada- resultan imprescindibles de cara a establecer la muestra a examinar. Así, se establecieron las siguientes acotaciones: iconográfica (la imagen de Cristo crucificado), tipológica y material (la producción escultórica en piedra y madera), territorial (Galicia) y cronológica (el siglo XIV).

3 La primera delimitación establecida fue la iconográfica. La elección de la imagen del Crucificado como foco de estudio se ajusta a la realidad religiosa bajomedieval, pues se produce entonces un giro en la consideración de Cristo, más centrada en su lado humano y no únicamente en su esencia divina. Por consiguiente, se produce un aumento en las devociones cristológicas y en las imágenes de Cristo en la cruz. En cualquier caso, debe partirse de la premisa de que el Crucificado es -por razones obvias- uno de los tipos iconográficos más habituales de la producción visual medieval ${ }^{2}$.

4 En cuanto a la elección tipológica y material, al centrar el estudio en la producción escultórica en piedra y madera se dejaban fuera del corpus todas las piezas llevadas a cabo en otros materiales o técnicas, como la pintura, la orfebrería, la miniatura o la eboraria. La preferencia por la escultura se fundamenta en la diferencia cuantitativa de vestigios conservados si se compara con otros materiales -a excepción de la orfebrería-, así como en la diversidad de usos y configuraciones que presentan las imágenes en estos medios. Es decir, la escultura resulta más versátil a la hora de aproximarse al uso de las imágenes, permitiendo examinar múltiples contextos espaciales, tipos de piezas y técnicas.

5 Se estableció también una acotación territorial centrada en Galicia. Resulta cuando menos complejo la creación de una delimitación territorial a la hora de aproximarse al pasado, pues existe el peligro de extrapolar las concepciones contemporáneas del espacio a la realidad medieval. Esta delimitación, a pesar de su proximidad con la actual demarcación político-territorial de Galicia, responde también a la existencia de una entidad territorial con límites similares durante los siglos medievales: el reino de Galicia, enmarcado desde 1230 en la Corona de Castilla.

6 Finalmente, se decidió fijar el marco temporal en el siglo XIV. Somos conscientes de que la concreción de un marco cronológico que abarque de 1300 a 1400 resulta ajeno a la realidad histórica a la que se aproxima el trabajo, pues las funciones de la imagen no varían con el paso del siglo XIV al XV. Sin embargo, esta acotación resultaba necesaria de cara a poder establecer una muestra abarcable. La elección de este marco cronológico vino determinada por una serie de razones. Más allá del hecho de tratarse de un contexto en el que tienen lugar grandes cambios sociales, políticos y religiososcon su consiguiente impacto en la producción visual-, existen una serie de justificaciones específicas relativas al caso gallego. Así, es en esta centuria cuando las producciones visuales en Galicia asimilan, de manera definitiva, los códigos visuales asociados al sistema representativo gótico, que tienen un impacto en el modo de representar a Cristo crucificado, con unas nuevas formulaciones visuales en correspondencia con los discursos teológicos y con la realidad social del momento. Además de los cambios en las características formales y estéticas, se producen en esta centuria novedades a otros niveles. Por ejemplo, aumenta el número de piezas fabricadas, la producción se vincula a nuevos comitentes, se multiplican las tipologías escultóricas y, consecuentemente, se diversifican los usos asociados a ellas. Finalmente, cabe destacar que, como había puesto de manifiesto Serafín Moralejo, es precisamente 
a partir de 1300 cuando se produce una revitalización en la labor escultórica en este territorio, que había sufrido un estancamiento en las décadas anteriores ${ }^{3}$. En definitiva, la decisión de centrar este trabajo en el siglo XIV se basa en que esta centuria supone el culmen de una serie de cambios que luego se mantendrán durante los siglos posteriores, tanto a nivel iconográfico como tipológico y funcional.

En cualquier caso, aunque se hayan establecido estas delimitaciones, resulta fundamental destacar que a lo largo del trabajo esas fronteras son traspasadas en numerosas ocasiones a través de la aplicación de análisis comparativos. De este modo, son constantes las referencias tanto a otras realidades territoriales y culturales como cronológicas y materiales. Esta aproximación muestra el interés de presentar una forma más holística de entender los sistemas culturales, las sociedades y la reconstrucción del pasado a través de sus diversos vestigios materiales.

El resultado de la búsqueda y selección de piezas nos aportó, como era de esperar, una muestra enormemente heterogénea formada por esculturas de diversas tipologías: tallas en madera, cruces de piedra exentas, sarcófagos o varios relieves pétreos. Esta diversidad del material a estudiar conllevó que, consecuentemente, fuese necesario aproximarse a ellas de distintos modos, pues la pretensión final de esta investigación no era únicamente la de plantear un estudio formalista o iconográfico, sino la de aproximarse al objeto desde la perspectiva de la Historia Cultural, tratando también aspectos relativos a las funciones y recepción de la imagen, de modo que pudiésemos construir un relato sobre la cultura religiosa de la época y el papel que estos objetos tuvieron en ella.

Esta diversidad, tanto en la muestra como en el modo de estudiar las piezas, trajo como consecuencia una de las mayores problemáticas a la hora de realizar este trabajo: el modo en el que organizar el material de una forma coherente. Finalmente, establecimos una estructura en tres bloques, divididos a su vez en diversos capítulos destinados a temáticas específicas.

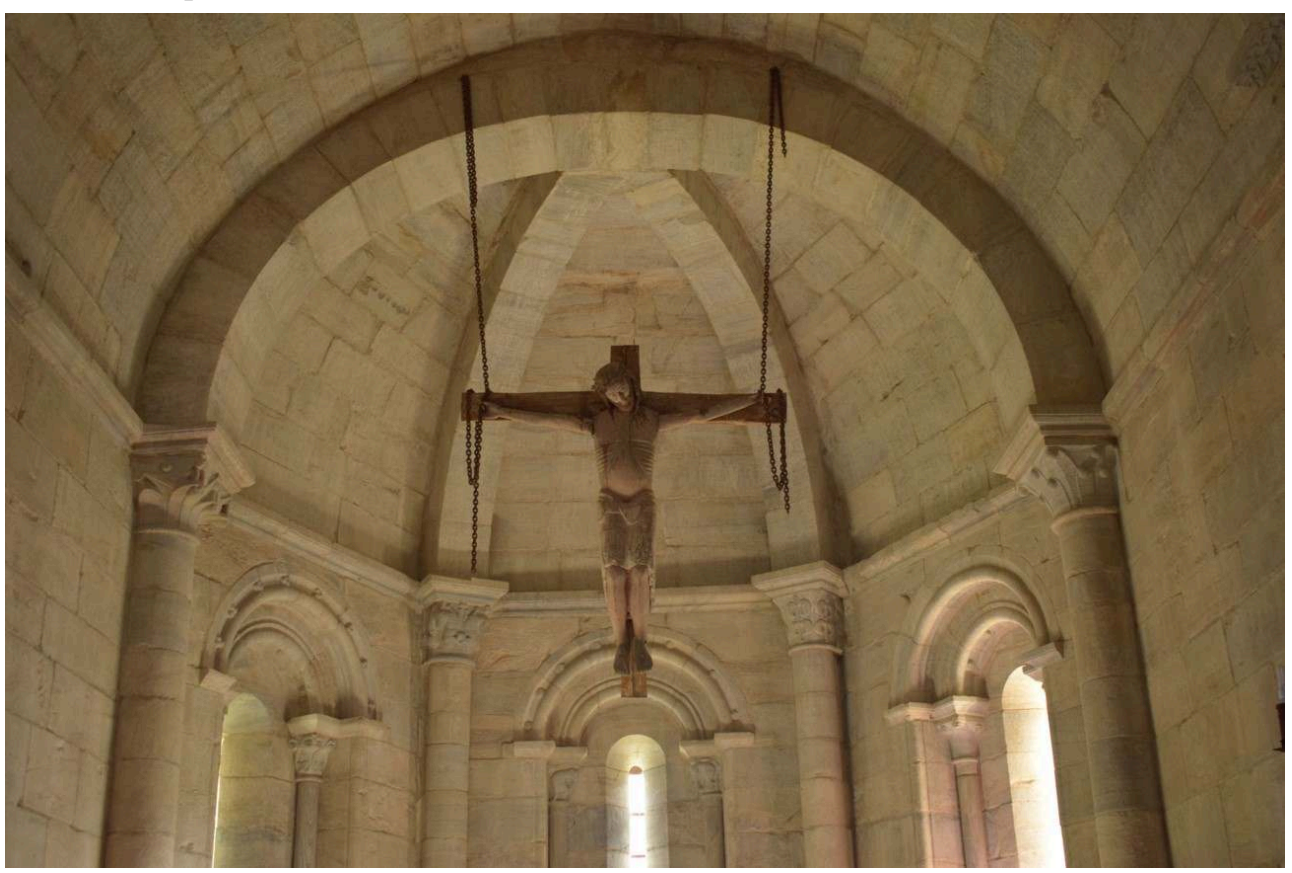

Fig. 1 - Crucificado, San Pedro Fiz de O Hospital, ca. 1300, (O Incio, Lugo) ${ }^{4}$ 
10 El primer bloque, compuesto de dos capítulos unificados bajo el título Marco Inicial, tiene como finalidad establecer una visión panorámica de la evolución de la imagen de Cristo crucificado, tanto a nivel europeo como centrado en el caso específico de Galicia. Así, el primer capítulo se dedica a la síntesis de la evolución de esta imagen, planteando un recorrido por el desarrollo y transformaciones que esta experimentó desde sus orígenes hasta finales de la Edad Media, conectando dichas variaciones con la realidad social y espiritual del momento. Además, decidimos incluir también un apartado en el que aludimos a las resistencias que se producen ante la introducción de modificaciones en las imágenes religiosas. Para ello nos centramos en un texto del obispo Lucas de Tui, en el que el obispo tudense asocia uno de los grandes cambios que tuvo lugar en la imagen del Crucificado -el paso de cuatro a tres clavos- con uno de los movimientos heréticos más importantes del momento: los albigenses ${ }^{5}$.

11 El segundo capítulo recoge los cambios que experimenta esta imagen en el caso específico de Galicia, aludiendo a las piezas conservadas en este territorio fundamentalmente entre los siglos XIII y XV. Este capítulo tiene dos finalidades: por un lado, hacer un recorrido a nivel formal presentando las variaciones en la plasmación de las esculturas conservadas; mientras que, por otro lado, se plantea una primera aproximación a las funciones de estas piezas, creando así una base que sirve de punto de partida para los estudios específicos que se plantean en los capítulos siguientes, donde el foco se centra en la diversificación de funciones de las imágenes del Crucificado ${ }^{6}$.

El segundo bloque, Imágenes más allá del altar, tiene como elemento vertebrador la presencia de imágenes más allá de estos espacios, mostrando cómo las funciones asociadas a las piezas llevaron a que estas abandonasen temporal o permanentemente sus emplazamientos estáticos habituales. Para ello se plantearon tres capítulos dedicados al estudio de tres tipos de producción diferentes y de los usos que se habrían hecho de ellos.

13 El primer capítulo se centra en el desplazamiento de imágenes del Crucificado como parte de ritos litúrgicos, remitiendo esencialmente a la liturgia de funerales. Para ello se estudia la presencia de imágenes en procesiones y otros puntos de la liturgia de difuntos a través del análisis de un caso específico: el sepulcro del "obispo desconocido" de la Catedral de Ourense (ca. 1320) (Fig. 2)7. El análisis de este monumento nos llevó a reflexionar sobre la representación de imágenes dentro de otras imágenes, pues en este monumento el Crucificado no es representado como referencia al episodio bíblico, sino como objeto, es decir, como simulacro. Así, presentamos los relieves de este sepulcro en los que se figura parte de la liturgia de difuntos- como fuente visual que aporta información histórica a través de la que poder conocer el uso que se hacía de estos artefactos en la Galicia del siglo XIV, mostrándolos como un tratado litúrgico visual en el que la propia escultura reflexiona sobre los usos de la imagen ${ }^{8}$. Aun siendo conscientes de que la figuración de la liturgia de funerales en los sepulcros habría devenido en la producción escultórica del siglo XIV un motivo estereotipado que no necesariamente remite a una realidad específica, en este capítulo planteábamos la posibilidad de que los crucifijos representados en este sepulcro remitiesen al Cristo de los Desamparados (ca. 1200), la única talla en madera que habría existido en la catedral de Ourense cuando se llevó a cabo este monumento, que además comparte características formales con los crucificados de los relieves. 


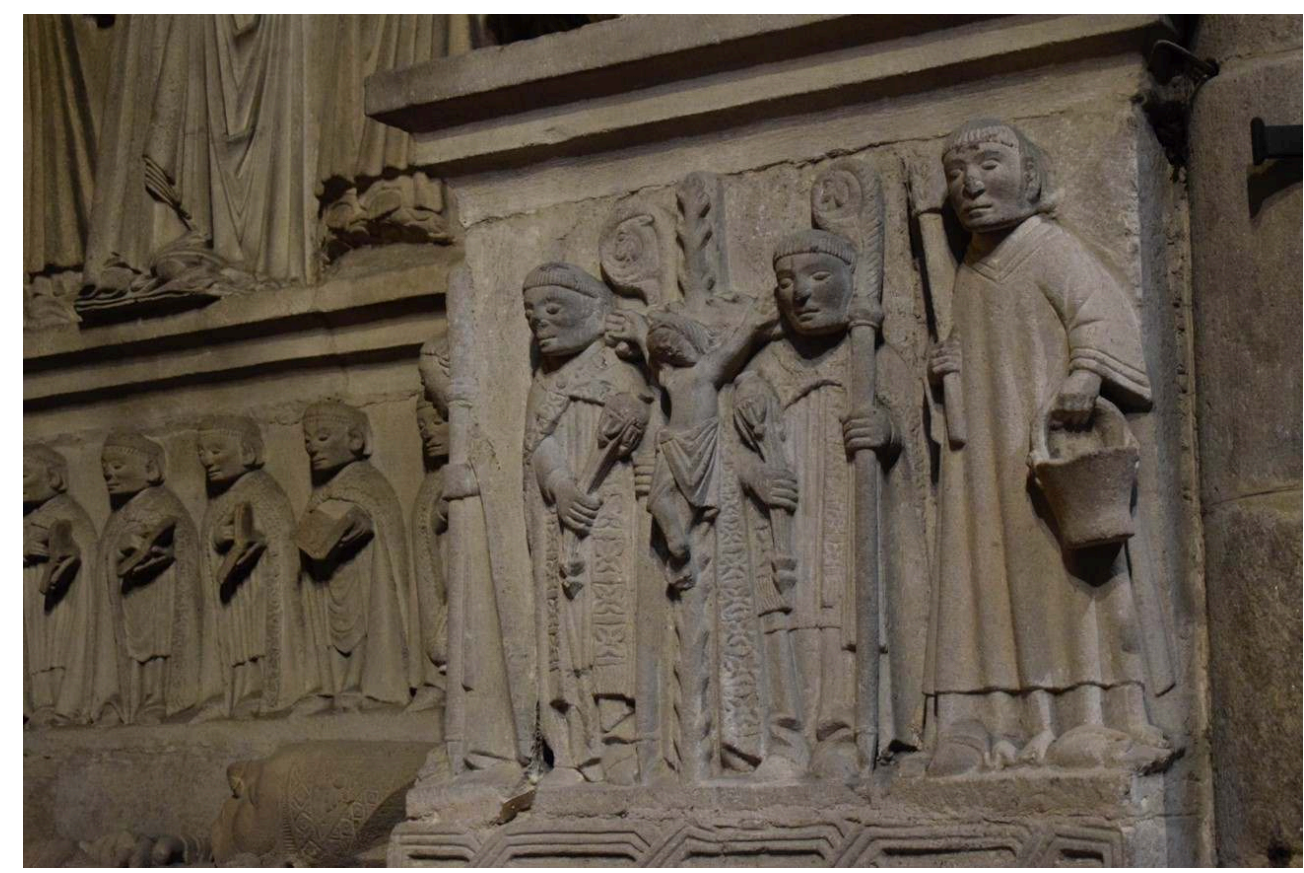

Fig. 2 - Sepulcro del "obispo desconocido", ca. 1320, Catedral de Ourense (capilla mayor).

14 El segundo capítulo trata el empleo de esculturas durante las puestas en escena teatrales y el modo en el que estas piezas se adaptaron morfológicamente a la diversificación de sus funciones, incorporando nuevos mecanismos que permitían su movimiento. En el caso de los crucificados, estos eran utilizados durante Pascua para representar la Pasión y el Descendimiento de Cristo, siendo documentado el uso de este tipo de esculturas por primera vez en el siglo XIV, en el Ordinarium Barkingense (Essex, ca. 1363-1367) ${ }^{9}$.

15 En lo que respecta a Galicia, no se conservan fuentes textuales que confirmen la existencia de este tipo de puestas en escena del Descendimiento, sin embargo, la presencia de estas esculturas nos lleva a confirmarla. De este modo, las propias imágenes son presentadas, nuevamente, como la fuente histórica principal a través de la que reconstruir el pasado. Para ello, remitimos en esta tesis a los cinco crucificados gallegos que han sido identificados como articulados ${ }^{10}$, pero proponiendo nuestras dudas sobre uno de ellos, el crucificado de O Incio (Lugo) (Fig. 1), pues durante el trabajo de campo no pudimos comprobar la existencia de articulaciones en los brazos.

Las articulaciones de estas esculturas podían alcanzar diversos grados de complejidad, desde las simples articulaciones en los hombros para permitir el movimiento de los brazos hasta la incorporación de articulaciones en la cabeza, los codos, las manos, la cadera o las rodillas. De los casos gallegos, dos de ellas muestran sistemas de articulación enormemente complejos: los Santos Cristos de Ourense (Fig. 3) y Fisterra (ca. 1330-1340) ${ }^{11}$. Debido a la excepcionalidad de estas esculturas buena parte de este capítulo se dedicó a su estudio, pues permitieron además la aproximación al empleo de nuevas técnicas y materiales en la producción escultórica: como recubrimientos, rellenos que hacen las esculturas blandas al tacto, o postizos. El empleo de estas nuevas técnicas hace que las esculturas se alejen de las simples tallas en madera policromadas, para configurar nuevos objetos que permitían la experiencia táctil de las imágenes. 


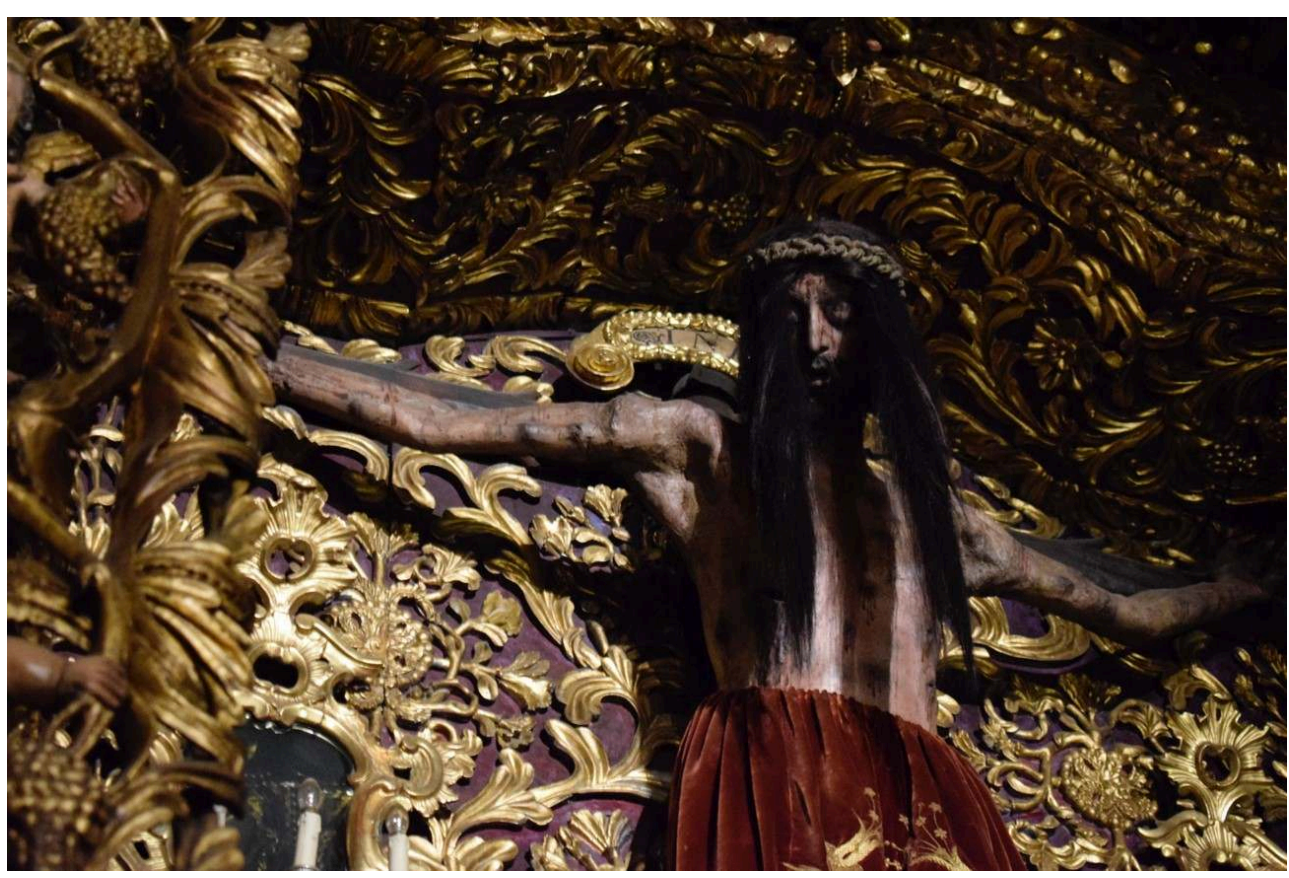

Fig. 3 - Santo Cristo de Ourense, ca. 1330-1340, Capilla del Santo Cristo (Catedral de Ourense).

17 El estudio de estas piezas también nos llevó a examinar otros aspectos más allá de sus características físicas, aludiendo a cuestiones como la tridimensionalidad, el naturalismo, la sensación de presencia provocada por estas esculturas o a la idea de "imágenes vivas"12. A respecto de este último punto, fue habitual en la cultura bajomedieval que a las imágenes les fuesen asociadas capacidades de animación, es decir, que las imágenes eran asimiladas al ser humano, asociándoseles capacidades físicas similares a las nuestras, como pueden ser la habilidad de moverse, llorar o que les creciese el pelo. Este tipo de propiedades podrían ser asociadas a un objeto independientemente de su apariencia física, sin embargo, para el caso de las esculturas gallegas, consideramos que el naturalismo representativo y el uso de esos nuevos materiales jugaron un papel central en su identificación como algo similar a un ser humano ${ }^{13}$.

18 Finalmente, el tercer capítulo de esta segunda parte se dedica al estudio de los cruceiros, cruces de piedra que a partir del siglo XIV comenzaron a disponerse en los espacios públicos -como plazas o caminos- convirtiéndose en nuevos elementos sacralizadores del paisaje medieval. Este tipo de monumento llevó a que las imágenes que habitualmente se encontraban en el interior de los templos abandonasen el entorno de las iglesias para encontrar nuevas localizaciones en los espacios cotidianos de la gente. Así, las imágenes que habitualmente se encontraban en los altares -como el Calvario, la Virgen con el Niño o las imágenes de santidad- aparecen ahora en cementerios, plazas, caminos o en las salidas de los núcleos poblacionales ${ }^{14}$.

En este capítulo, en primer lugar, aportamos nuestros argumentos para justificar por qué consideramos que estas cruces de piedra fueron originariamente una producción medieval, datando los primeros ejemplares conservados en el siglo XIV. Además, en esta tesis se propone una reconstrucción de cuáles habrían sido sus posibles funciones y localizaciones, concluyendo que se trata de construcciones multi-funcionales. Para poder llevar a cabo esta reconstrucción se partió de los propios vestigios conservados en Galicia, complementando su estudio con la aproximación a producciones foráneas, 
así como con el acceso a toda una serie de miniaturas y pinturas en las que se incluían representaciones de estas piezas que aportan datos fundamentales sobre la consideración medieval de las mismas.

Finalmente, se propone un análisis de los programas visuales de cuatro casos que consideramos del siglo XIV: los cruceiros de Fervenzas (Fig. 4), Melide, Neda y Vimianzo. Dichos programas remiten fundamentalmente a la historia de la redención, la Segunda Venida y a aquellos que han de interceder por los difuntos en el más allá. Esta aproximación nos llevó a vincular este tipo de monumentos con la nueva consideración bajomedieval de la muerte y con el miedo ante la posibilidad de ser condenado, conectándolos especialmente con la muerte no asistida o la mala muerte, que obligaría a cumplir una condena temporal en el Purgatorio ${ }^{15}$.

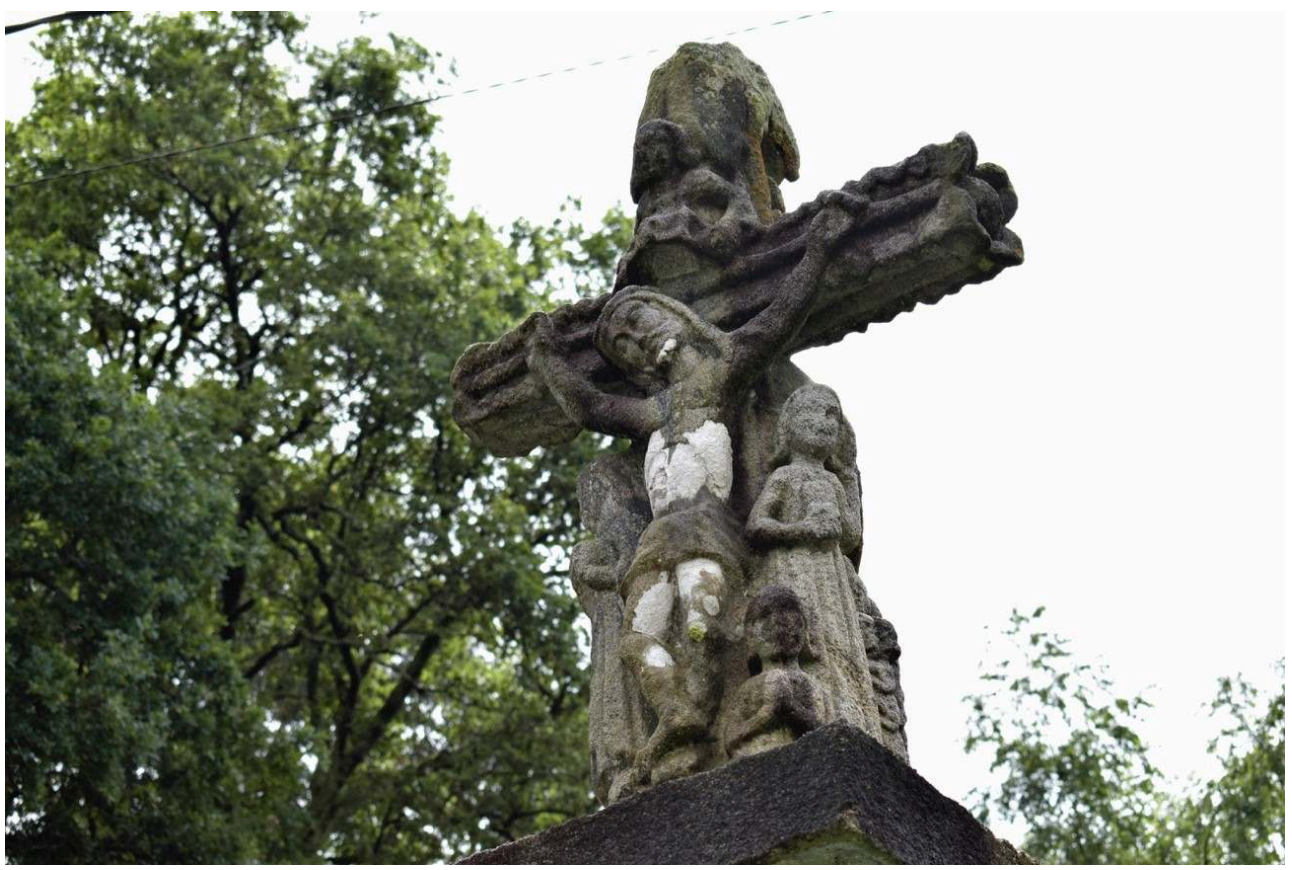

Fig. 4 - Cruceiro de Fervenzas, siglo XIV, San Vicente de Fervenzas (Aranga, A Coruña).

21 Por último, el tercer bloque, Las imágenes y la muerte, se dedica al estudio de las piezas que pertenecen o pertenecieron a ámbitos funerarios. Para ello se establecieron tres capítulos, el primero de ellos concebido como una aproximación a los cambios que tienen lugar en la consideración de la muerte durante la Baja Edad Media, pues la muerte, en su condición de hecho cultural, fue entendida de modos diferentes dependiendo de las realidades sociales.

22 El segundo capítulo se dedica a la figuración del Crucificado en los sepulcros. Cabe destacar que la figuración de Cristo crucificado fue habitual en la producción funeraria europea, conservándose numerosos ejemplos en los que esta imagen forma parte de sus programas visuales. De este modo, al aproximarnos a la escultura funeraria gallega partíamos de la hipótesis previa de que la imagen del Crucificado sería un recurso habitual, basándonos en la centralidad de esta temática en relación con la salvación del alma tras la muerte, así como en la interrelación que se crearía entre la muerte de Cristo y la del propio individuo. Sin embargo, el estudio de las esculturas conservadas llevó a descartar esta hipótesis inicial, pues para el caso gallego sobresale la escasez de ejemplos conservados si se lo compara con otros territorios. 

aparece como parte del calvario en la peana o yacija, de los cuales únicamente dos pueden ser datados con seguridad en el siglo XIV, el de Juana de Castro (ca. 1375) y el de Fernán Cao de Cordido (ca. 1377), ambos en Santiago de Compostela ${ }^{16}$. A mayores de estos dos ejemplares, contamos con un relieve que posiblemente hubiese formado parte de un arcosolio: el relieve que habría pertenecido al convento de San Francisco de Pontevedra, y que fuera datado por Dolores Fraga Sampedro en el siglo XIV $(1320-1340)^{17}$. de dos de ellos: el de Fernán Cao de Cordido y uno conservado en el claustro de la Catedral compostelana (Fig. 5). En el caso de Cao de Cordido su datación resulta sencilla, pues la indumentaria del yacente aporta un marco cronológico bastante específico que se corresponde además con la documentación asociada a este escudero. Sin embargo, el sepulcro del claustro despierta dudas en cuanto a su cronología, pues no contamos con elementos que ayuden a establecer un marco. De este modo, las referencias a su localización y el análisis estilístico de la pieza son las principales vías para poder aportar una datación. Así, aunque inicialmente consideramos que podría tratarse de una pieza del siglo XIV, finalmente proponemos una cronología de ca. $1400^{18}$.

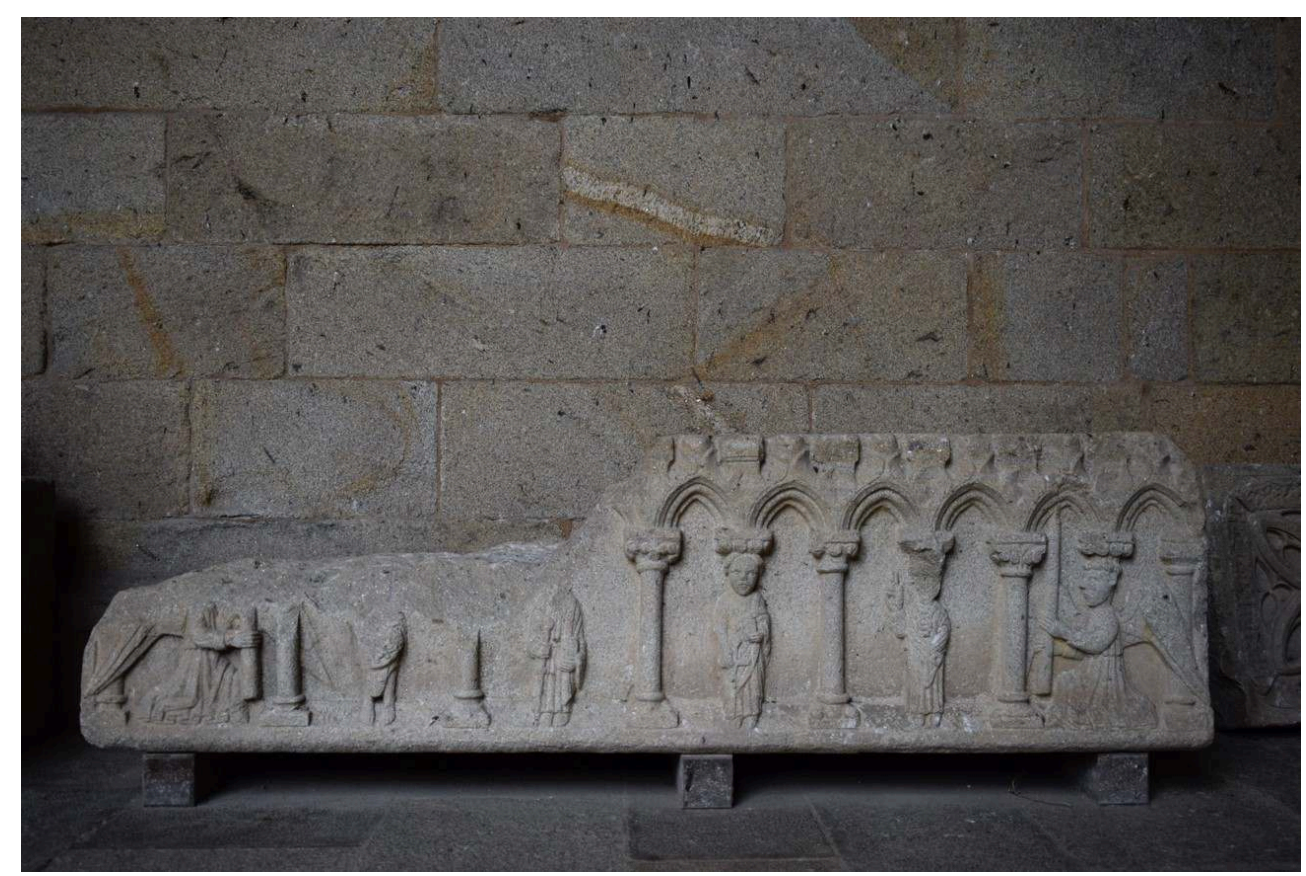

Fig. 5 - Sepulcro, claustro de la Catedral de Santiago, principios siglo XV (Museo Catedralicio, Santiago de Compostela).

Tras remitir a los programas de estos monumentos y a sus significados (aludiendo a su doble función en relación con la memoria y la salvación del difunto), nos referimos también a los talleres que habrían podido trabajar en ellos, encontrando en el caso de Cao de Cordido conexiones con Betanzos; mientras que para el sepulcro catedralicio planteamos la hipótesis de que se encontrase vinculado a un taller portugués que trabajó en Compostela desde el segundo tercio del siglo XIV, o bien al impacto que este habría tenido sobre la producción escultórica compostelana ${ }^{19}$. 

figuras orantes extemporales que son introducidas en la escena del Calvario (Fig. 6). Más allá de las funciones conmemorativas que podría tener este tipo de figuraciones que aludiría a los promotores, remitimos a otros posibles significados. En primer lugar, aludimos a como esta configuración visual podría ser entendida como una materialización retórica de la esperanza en la salvación futura del donante (en línea con las propuestas de Rosa Alcoy), mostrándose en estas escenas la relación entre el fiel y la divinidad ${ }^{20}$. Además, planteamos también la posibilidad de que estas figuras funcionasen como elementos puente entre la realidad del fiel y la realidad representativa, incidiendo en cómo podrían haber servido de estrategias comunicativas que buscaban una respuesta activa en los espectadores, al mostrarles modelos visuales que incitarían a la imitación. específicas que constituyeron nuestra muestra, estudiamos el papel que estos objetos habrían tenido en la cultura religiosa de la Galicia del siglo XIV. Nos aproximamos a la forma en la que las imágenes eran creadas, vistas, entendidas y sentidas, teniendo en cuenta aspectos como los espacios, la producción, la diversidad de usos o la recepción que podrían haber tenido ciertas piezas.

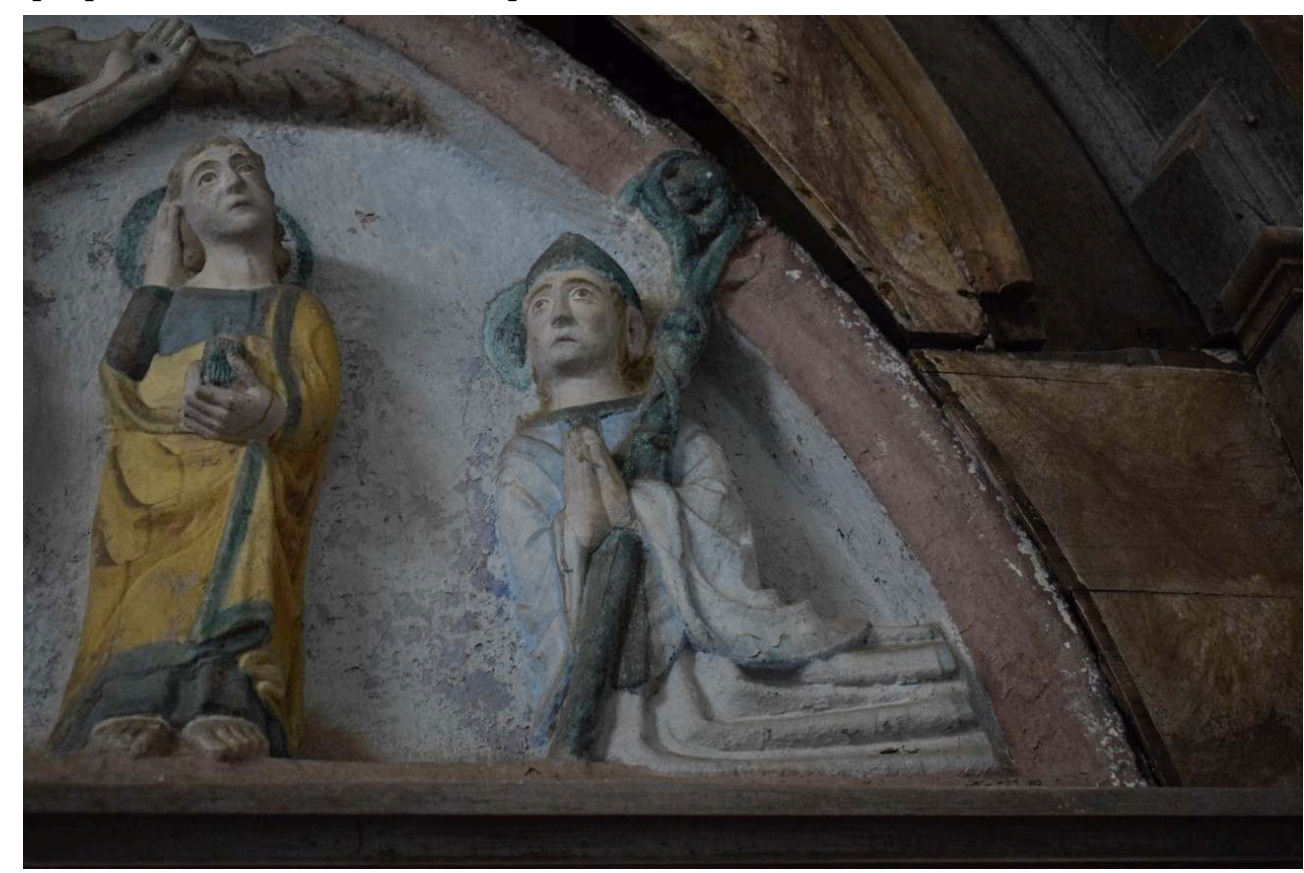

Fig. 6 - Relieve de Nuestra Señora de Belén, ca. 1322-1323 Santa Cristina de Fecha (Santiago de Compostela).

A través de este trabajo verificamos cómo, junto al aumento en la producción de esculturas de Cristo crucificado en Galicia en el siglo XIV, se produce también un incremento en la diversidad de tipologías, soluciones visuales, localizaciones y funciones para las que estas piezas son destinadas. Así, es en esta centuria cuando se generaliza la producción de sepulcros figurados o cuando comenzaron a ser creadas nuevas piezas, como los crucificados articulados o las cruces de piedra figuradas.

Junto al habitual acceso a las imágenes del Crucificado a través de su disposición en el presbiterio y en otras capillas, pueden ser identificados otros usos que conllevaron diferentes aproximaciones de la imagen al espectador. Esto es lo que sucede cuando 
esta imagen es desplazada como parte de ritos litúrgicos o de puestas en escena; cuando nuevas tipologías como los cruceiros sacan a los espacios públicos las imágenes que habitualmente se encontraban en el interior de las iglesias; o cuando esta imagen es incluida en los programas visuales de monumentos funerarios, que pueden ser encontrados en diversidad de localizaciones.

Finalmente, otro de los objetivos principales de nuestra investigación era observar hasta qué punto Galicia respondía a las realidades presentes en otros territorios del Occidente medieval, partiendo de la idea de que los reinos cristianos medievales presentan -hasta cierto punto- un carácter bastante homogéneo, pues se enmarcan en un sistema religioso común. Puede concluirse que la producción escultórica presente en Galicia responde a una homogeneidad cultural e ideológica que refleja una hegemonía cultural común que engloba todo el Occidente europeo cristiano. Así, aunque Galicia a priori podría ser considerado un territorio periférico, pudo comprobarse cómo es un área que participa de las corrientes internacionales.

31 Nuestro objetivo era ofrecer nuestra aportación a la reconstrucción de la cultura medieval en Galicia a través de las imágenes. De este modo, el estudio de estas esculturas ha aportado valiosas evidencias sobre las experiencias de los fieles cristianos de la Galicia de finales de la Edad Media.

\section{NOTAS}

1. Esta investigación fue financiada por la Xunta de Galicia (Axudas de apoio á etapa predoutoral, 2016) y realizada en el marco del grupo de investigación Medievalismo: espacio, imagen y cultura (GI-1507) de la Universidad de Santiago de Compostela. La consulta de esta tesis doctoral puede ser solicitada a través del repositorio institucional MINERVA en el siguiente enlace:

https://minerva.usc.es/xmlui/handle/10347/23226.

2. Son numerosos los trabajos en los que se ha abordado de alguna forma esta temática. En un primer momento se realizaron estudios formales e iconográficos que plantearon la evolución de esta imagen, entre los que cabe destacar el trabajo de Paul Thoby por constituir el primer estudio monográfico de este tipo. THOBY, Paul - Le crucifix des origines au Concile de Trente. Étude iconographique, 2 vols. Nantes: Bellanger, 1959. Posteriormente se desarrollaron estudios especializados centrados en cronologías, tipologías o aspectos concretos, entre los que podemos citar a modo de ejemplo las aportaciones de: RAW, Barbara C. - Anglo-Saxon Crucifixion Iconography and the Art of the Monastic Revival. Cambridge: Cambridge University Press, 1990; CHAZELLE, Celia - The Crucified God in the Carolingian Era. Theology and Art of Christ's Passion. Cambridge: Cambridge University Press, 2001; MULLINS, Juliet, NÍ GHRÁDAIGH, Jenifer y HAWTREE, Richard (eds.) - Envisioning Christ on the Cross: Ireland and the Early Medieval West. DublínPortland: Four Courts Press, 2013. Para el caso gallego, el único estudio que había abordado las imágenes del Crucificado de un modo conjunto es la aportación de Carmen Manso Porto en la colección Galicia. Arte, donde la autora establece la evolución formal de las tallas en madera del Crucificado en Galicia. MANSO PORTO, Carmen - "Relieves y 
retablos. Imaginería". in RODRÍGUEZ IGLESIAS, Francisco (dir.) - Galicia. Arte, XI: Arte Medieval (II). A Coruña: Hércules, 1993, pp. 414-455. Para un acercamiento más completo a la literatura científica sobre este tipo iconográfico remitimos a nuestra tesis doctoral.

3. Moralejo afirma que el hecho de que durante el siglo XIII no se afiance el gótico en Galicia (que se encontraba presente ya durante las primeras décadas de esa centuria en la Catedral de Tui), "no se debe, como se ha dicho muchas veces, a la pervivencia de la tradición regional; la relación entre uno y otro hecho es en realidad la de coefectos de la inasistencia de condiciones económicas y políticas más propicias". MORALEJO ÁLVAREZ, Serafín - "Escultura gótica en Galicia, 1200-1350". in FRANCO MATA, Ángela (coord.) - Patrimonio artístico de Galicia y otros estudios, I. Santiago de Compostela: Dirección Xeral de Patrimonio, 2004, p. 77.

4. Todas las imágenes utilizadas en este artículo son de autoría propia.

5. Lucas de Tui dedica un capítulo de su obra teológica, De altera uita fide que controversiis adversus albigensian errors (ca. 1235), a rechazar esta innovación en la figuración del Crucificado: Contra illos qui dicunt, tres tantum clauos fuisse fixos in manibus et pedibus Saluatoris (Libro II, Capítulo 11). Para la consulta en latín véase la edición: FALQUE REY, Emma (ed.) - Lucae Tudensis. De altera vita. Colección Corpus Christianorum. Continuatio Medievalis, 74A. Turnhout: Brepols, 2009. Traducido a castellano en: FALQUE REY, Emma - "La iconografía de la crucifixión en un tratado escrito en latín en el s. XIII por Lucas de Tuy". Laboratorio de arte 23 (2011), pp. 19-32. Para el cambio en el número de clavos, véase: CAMES, Gérard - "Recherches sur les origines du crucifix à trois clous". Cahiers archéologiques: Fin de l'Antiquité et Moyen Age 16 (1966), pp. 185-202.

6. En esta primera aproximación funcional, tras comprobar que una gran parte de las piezas conservadas son tallas en madera de gran tamaño, se alude al uso de estas esculturas en los altares, ya sea en el presbiterio o en otras capillas, un uso habitual de estas piezas, vinculado a la liturgia, el culto y la devoción - sea esta individual o colectiva. KROESEN, Justin E. A.; SCHMIDT, Victor M. (eds.) - The Altar and its Environment, 1150-1400. Turnhout: Brepols, 2010; SUREDA, Marc - "La imagen en el altar. Reflexiones sobre localización, propiedades y utilidades de la imagen esculpida a partir de ejemplos catalanes del medioevo". Codex Aquilarensis, 28 (2012), pp. 86-94.

7. MORALEJO ÁLVAREZ, Serafín - Escultura gótica en Galicia (1200-1350). Santiago de Compostela: Universidade de Santiago de Compostela, 1975. Tesis doctoral.; SÁNCHEZ AMEIJEIRAS, Rocío - "Sepulcro de obispo desconocido: ¿sepulcro del obispo don Gonzalo de Novoa (†1331)?”. in GARCíA IGLESIAS, José Manuel (ed.) - Camiño de Paz. Mane nobiscum domine. Santiago de Compostela: Consellería de Cultura, Comunicación Social e Turismo, 2005, pp. 163-172; CENDÓN FERNÁNDEZ, Marta - "La catedral de Ourense: receptáculo de la memoria de la sociedad medieval". Semata. Ciencias Sociais e Humanidades 22: El legado de las catedrales (2010), pp. 391-409.

8. Los estudios que trataron este tipo de figuración de imágenes dentro de imágenes, para las que se han utilizado términos como metapaintings, metapictures o images-withinimages, se centraban fundamentalmente en época moderna. Investigaciones recientes han asociado el inicio de este tipo de figuración con los siglos medievales. Para estos conceptos véase, entre otros: STOICHITA, Victor I. - The Self-Aware Image. An Insight into Early Modern Metapainting. Trad. Anne-Marie Glasheen. Turnhout: Harvey Miller, 2015 [1997]; MITCHELL, William J. T. - Teoría de la imagen. Ensayos sobre representación verbal y visual. Trad. Yaiza Hernández Velázquez. Madrid: Akal, 2009 [1994]; BOKODY, Péter - 
Images-within-Images in Italian Painting (1250-1350): Reality and Reflexivity. FarnhamBurlington: Ashgate, 2015.

9. Los primeros estudios que se encargaron de este tipo de esculturas fueron los trabajos de Gesine Taubert y Johannes Taubert. La monografía de Kamil Kopania aumentó el corpus de piezas identificadas, al incluir referencias a ámbitos culturales no contemplados anteriormente, encontrando en su trabajo algunas referencias a los casos gallegos. TAUBERT, Gesine; TAUBERT, Johannes - "Mittelalterliche Kruzifixe mit Schwenkbaren Armen: Ein Beitrag zur Verwendung von Bildwerken in der Liturgie". Zeitschrift des Deutschen Vereins fur Kunstwissensechaft 23 (1969), pp. 79-121; KOPANIA, Kamil - Animated Sculptures of the Crucified Christ in the Religious Culture of Latin Middle Ages. Varsovia: Neriton, 2010.

10. Cuatro de ellos del siglo XIV: el Santo Cristo de la iglesia parroquial de Santa María das Areas de Fisterra, el Santo Cristo de la Catedral de Ourense, el Crucificado de la iglesia de San Pedro Fiz do Hospital de O Incio y el Crucificado el conservado en el Museo Diocesano de Tui. Únicamente una de las esculturas data del siglo XV: el crucificado de la iglesia parroquial de Vilabade, en Castroverde (Lugo), cuya cronología sería posiblemente de hacia finales de dicha centuria. González Montañés remite a seis piezas en su estudio al entender que habría existido otra más en la iglesia de San Miguel de Pexegueiro (Tui), sustituida hoy por una pieza neo-medieval. Al no conservarse la pieza original no remitimos a ella en nuestra enumeración. GONZÁLEZ MONTAÑÉS, Julio I. - Drama e iconografía en el arte medieval peninsular (siglos XI-XV). Madrid: UNED, 2002. Tesis doctoral.

11. Esta complejidad habría sido aludida ya en estudios previos. Por ejemplo, Ferro Couselo y Lorenzo Fernández hacían referencia a las articulaciones de los hombros, los dedos y la cadera para el caso ourensano. Pero, además, esta complejidad puede confirmarse a través de los informes resultado de las restauraciones de estas esculturas. FERRO COUSELO, Jesús; LORENZO FERNÁNDEZ, Joaquín - "La capilla y santuario del Santísimo Cristo de la Catedral de Orense". Boletín Auriense, Anexo 12 (1988); FERNÁNDEZ SANTIAGO, Ángeles - "Intervención de conservación y restauración”. Camino de Santiago. Revista peregrina 13 (2010), pp. 28-30.

12. FREEDBERG, David - El poder de las imágenes. Estudios sobre la historia y la teoría de la respuesta. Madrid: Cátedra, 1992 [1989]; BACCI, Michele - “Imágenes sagradas, injertos orgánicos y simulación de corporeidad en la Edad Media". Codex Aquilarensis, 29: Imágenes en acción. Actos y actuaciones de las imágenes en la Edad Media (2013), pp. 99-116.

13. En este capítulo se alude a fuentes elaboradas a partir del siglo XVI en las que se han podido localizar referencias a la recepción posterior de estas esculturas medievales. Cabe destacar, por ejemplo: FLÓREZ, Enrique (ed.) - Viage de Ambrosio de Morales por orden del Rey D. Philipe II a los Reynos de León, y Galicia, y Principado de Asturias (...). Madrid, 1765 [1572]; PORREÑO, Baltasar - Nobiliario del Reyno de Galicia. Trad. Dolores Barral Rivadulla y Óscar Ares Botana. A Coruña: Ediciones Boreal, 1997 [ca. 1570]; VILLALBA Y ESTAÑÁ, Bartolomé; GAYANGOS, Pascual de (eds.) - El Pelegrino curioso y grandezas de España, I. Madrid: Sociedad de Bibliófilos Españoles, 1886 [ca. 1580].

14. Para un estudio en conjunto de los "monumentos públicos" de la Europa medieval véase: TIMMERMANN, Achim - Memory and Redemption. Public Monuments and the Making of Late Medieval Landscape. Turnhout: Brepols, 2017. Para el caso gallego, la primera 
aproximación monográfica a este tipo de monumentos fue la de Castelao, de la que parten las primeras hipótesis para su estudio: CASTELAO, Alfonso - As cruces de pedra na Galiza. Vigo: Galaxia, 1984 [1950]. Para un estudio historiográfico sobre esta obra véase: CARREÑO, Sara - "From Religious Artefacts to Symbols of Identity. The Role of Stone Crosses in Galician National Discourse". in HAWKES, Jane y TURNER, Philippa (eds.) The Rood in Medieval Britain and Ireland, c.800-c.1500. Woodbridge: Boydell\&Brewer, 2020, pp. 81-102. Para el estudio de los cruceiros véase también: VALLE PÉREZ, Xosé Carlos "Cruceiros". in OTERO PEDRAYO, Ramón - Gran Enciclopedia Gallega. Vol. VIII. Santiago de Compostela: 1974, pp. 49-59; BARRAL RIVADULLA, Mª Dolores; CENDÓN FERNÁNDEZ, Marta - "Devociones en piedra en la Galicia gótica rural". Semata. Ciencias Sociais e Humanidades 9: Espacios rurais e sociedades campesiñas (1998), pp. 405-423.

15. Un planteamiento en línea con las hipótesis de Elvira Mocholí Martínez para el caso valenciano. MOCHOLÍ MARTÍNEZ, Elvira - "Cruces, caminos y muerte". in GARCÍA MAHIQUES, Rafael; ZURIAGA SENENT, Vicent Francesc (coords.) - Imagen y cultura. La interpretación de las imágenes como historia cultural, II. Gandía: Biblioteca Valenciana, 2008, pp. 1097-1116.

16. Además de estos dos ejemplos, se conservan otras dos yacijas en las que se figura el Calvario: la conservada en el claustro de la Catedral de Santiago de Compostela, a la que aludiremos a continuación, y la conservada en las ruinas de Santo Domingo de Pontevedra (Museo de Pontevedra, siglo XV), que habría pertenecido a algún miembro de la familia de los Soutomaior.

17. FRAGA SAMPEDRO, M Dolores - "Un calvario peculiar: el franciscano orante al pie de la cruz". Quintana 2 (2003), pp. 161-172.

18. Este sepulcro aparece en las fichas de los catálogos de: REQUEJO ALONSO, Ana Belén - El arte medieval en los museos compostelanos: el museo de la catedral de Santiago de Compostela. Memoria de licenciatura inédita. Santiago de Compostela: 2000; YZQUIERDO PEIRÓ, Ramón - Las colecciones de arte de la Catedral de Santiago: estudio museológico. Santiago de Compostela: Universidade de Santiago de Compostela, 2015. Tesis doctoral.

19. Este taller portugués, vinculado al Mestre Pêro de Coimbra - el centro escultórico más importante del norte de Portugal - traería consigo las soluciones y modelos presentes en el área conimbricense, difundidos por Galicia durante la segunda mitad del siglo XIV y el siglo XV. Sobre este taller véase: NÚÑEZ RODRÍGUEZ, Manuel - "La Virgen de la $\mathrm{O}$ del antiguo trascoro de la catedral compostelana y su filiación conimbricense". Seminario de Estudios de Arte y Arqueología 47 (1981), pp. 409-415; DIAS, Pedro - "A pedra de Ançã, a escultura de Coimbra e a súa difusión en Galicia". in VALLE PÉREZ, Xosé Carlos (coord.) - Do tardogótico ó manierismo. Galicia e Portugal. A CoruñaLisboa: Fundación Pedro Barrié de la Maza - Fundação Calouste Gulbenkian, 1995, pp. 9-24. Para un estudio de la imagen del Crucificado en la escultura funeraria portuguesa: MELO, Joana Râmoa - Christus Patiens: representações do Calvário na escultura tumular medieval portuguesa. Lisboa: Edições Colibri, 2008.

20. ALCOY, Rosa - Anticipaciones del Paraíso. El donante y la migración del sentido en el arte occidental medieval. Gasteiz-Buenos Aires: Sans Soleil Ediciones, 2017. Véase también: JONES, Lars R. - "Visio Divina? Donor Figures and Representations of Imagistic Devotion: The Copy of the 'Virgin of Bagnolo' in the Museo dell'Opera del Duomo, Florence". Studies in the History of Art 61 (2002), pp. 31-55. 


\section{AUTOR}

\section{SARA CARREÑO}

Universidade de Santiago de Compostela, 15782, Santiago de Compostela, España.

sara.carreno@usc.es. https://orcid.org/0000-0003-3804-5733 